\title{
Stromatolites as archives for novel isotope proxies to reconstruct microbial habitats through deep time
}

\author{
DR. SIMON V. HOHL ${ }^{1}$ AND SEBASTIAN VIEHMANN ${ }^{2}$
}

${ }^{1}$ Tongji University

${ }^{2}$ University of Vienna

Presenting Author: sv_hohl@tongji.edu.cn

For the longest time in Earth's history, life evolved in microbial communities. It is, however, still incompletely understood how, when and where their habitats formed and how microbial communities adopted to drastic changes of the atmosphere-hydrosphere-lithosphere systems through deep time. Stromatolites, i.e., lithified microbial mats that occur in sedimentary successions from at least 3.4 billion years ago until today, may hold the geochemical key to our understanding of the evolution of microbial life on Earth and may also provide a blueprint for planetary studies. We here show how novel isotope applications in stromatolites can be used to reconstruct the environmental conditions of the habitats in which the earliest life on Earth thrived. Although the behaviour and fractionation processes in stromatolites and microbial mats are partly incompletely understood, the different isotope proxies (such as $\mathrm{Fe}, \mathrm{Mo}, \mathrm{Cr}, \mathrm{U}, \mathrm{Cd}$ and $\mathrm{Ba}$ ) have unique potential to better understand redox conditions, metal availability and (biogenic) metal cycling processes in microbial habitats. We provide deep insights into each isotope application and its future perspectives to bridge the gap between geochemistry and microbiology and better understand the evolution of microbial life on Earth and beyond. 